\title{
Infective Endocarditis: Rationale for Revised Guidelines for Antibiotic Prophylaxis
}

\author{
Prabhakaran P. Gopalakrishnan, MD; Sanjay K. Shukla, PhD; and Tahir Tak, MD, Ph.D, FACC
}

Keywords:

Antibiotics

Cardiac valves

Endocarditis prophylaxis

Infections

Infective endocarditis

Microbiology

Reprint Requests: Tahir Tak MD, PhD

Cardiovascular Diseases

Mayo Clinic

200 First Street SW

Rochester, MN 55905 USA

Tel: 507-284 294I

Fax: 507-266-7929

Email: tak.tahir@mayo.edu

Received: January 27, 2009 Revised:April 14, 2009

Accepted:April 29, 2009

doi: $10.3121 / \mathrm{cmr} .2009 .848$
I

nfective endocarditis is an uncommon but serious and often life-threatening condition. While developments in cardiac imaging, therapeutics and surgical techniques have led to improved outcomes in individual patients, the overall incidence of infective endocarditis has remained relatively stable from 1950 through 2000 , i.e., about 3.6 to 7.0 cases per 100,000 patient-years. ${ }^{1}$ The predisposing risk factors have changed over time with the emergence of intravenous drug abuse, intravascular prostheses, nosocomial exposure, hemodialysis, and age-related valvular sclerosis as more prevalent than rheumatic heart disease, especially in the developed countries. ${ }^{2}$ In addition to the risk factors, studies show that the causative flora implicated in infective endocarditis have also evolved, with Staphylococcus aureus emerging as the predominant pathogen, while a recent population-based study disputes this. ${ }^{3}$

Infective endocarditis is characterized by the presence of vegetations composed of platelets, fibrin, microorganisms, and inflammatory cells. The pathogenesis of infective endocarditis involves a complex sequence or confluence of events. ${ }^{4}$ Endothelial damage caused by turbulent blood flow seen in congenital or acquired heart disease causes platelets and fibrin deposition leading to formation of non-bacterial thrombotic endocarditis (NBTE). In this setting an episode of bacteremia could result in bacterial adherence to NBTE, bacterial proliferation within the NBTE, and formation of vegetations, the typical lesions of infective endocarditis (figure 1).

\section{Empiric Approach to Infective Endocarditis Prophylaxis: Caution is the Watchword!}

Prevention of infective endocarditis, potentially a life-threatening condition, has been given serious consideration by the entire medical community including physicians, surgeons, and dentists. Guidelines for preventing infective endocarditis related to medical procedures have been developed by professional societies like the American Heart Association (AHA) since the 1950s. The guidelines were empiric, formulated based more on pathophysiology and expert opinion and less on clinical evidence. Since both endothelial injury and a precipitating event causing bacteremia are requisite for development of infective endocarditis, patients with risk factors for endothelial injury undergoing medical procedures which can cause transient bacteremia were construed to be at high risk for developing infective endocarditis. Since certain groups of bacteria (eg, Streptococci, Staphylococci, Enterococci) are commonly known to adhere to nonbacterial thrombotic endocarditis (NBTE) causing infective endocarditis, procedures which caused bacteremia from these organisms were considered as high risk procedures. Prevention of bacteremia 


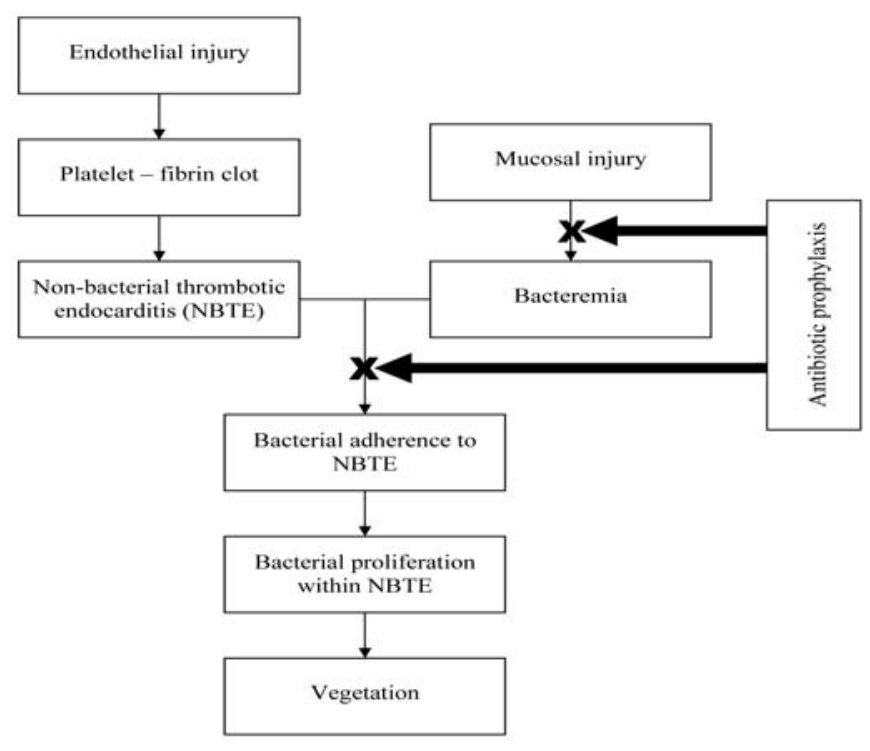

Figure 1. Pathogenesis of infectious endocarditis and rationale for antibiotic prophylaxis.

with appropriate antibiotics could in theory prevent or reduce bacteremia and prevent bacterial colonization of NBTE and thereby minimize the risk of infective endocarditis (figure 1). The bone of contention among the various guidelines and revisions is defining the patient population at high risk for cardiac endothelial injury and procedures with high risk for bacteremia.

\section{Evidence-Based Approach to Infective Endocarditis Prophylaxis: Do no Harm!}

While in theory, use of appropriate antibiotic prophylaxis for bacteremia causing procedures in patients with cardiac risk factors should lead to decreased incidence of infective endocarditis, this has not borne out in studies. Several factors contribute to the failure of this seemingly sound empirical approach. It is common knowledge, and studies have shown, that procedures like dental extraction cause bacteremia, but so do everyday activities like brushing teeth. While the degree of bacteremia caused by routine activities at a particular point in time may or may not be on the same magnitude as dental procedures, the overall burden of bacteremia over extended periods of time from daily activities would definitely surpass the transient bacteremia seen after medical procedures. The cumulative exposure to bacteremia from routine daily activities in 1 year may be as high as $5.6 \times 10^{6}$ times greater as that resulting from a single tooth extraction. ${ }^{5}$ Studies have shown only a small fraction, if any, of the infective endocarditis cases were probably caused by dental procedures ${ }^{6,7}$ Another weak link is the efficacy of antibiotic prophylaxis in preventing or reducing bacteremia, as this is the main argument for empiric approach. The evidence for bacteremia reduction or prevention by antibiotic prophylaxis is conflicting. ${ }^{8-11}$ Even studies which show reduction in bacteremia do not show reduction in infective endocarditis. ${ }^{89}$ While studies in dental procedures have failed to show a clear benefit for antibiotic prophylaxis, studies in other procedures (respiratory, gastrointestinal, and genitourinary) are very limited.

Table 1. Comparison of guidelines for infective endocarditis prophylaxis (1997-2008).

\begin{tabular}{|c|c|c|c|c|c|c|c|}
\hline \multicolumn{2}{|l|}{ Guidelines } & $\begin{array}{l}\text { AHA } \\
1997^{17}\end{array}$ & $\begin{array}{l}\text { SPILF/ } \\
\text { SFC 2002 }\end{array}$ & $\begin{array}{l}\text { ESC } \\
2004^{19}\end{array}$ & $\begin{array}{l}\text { BSAC } \\
2005^{20}\end{array}$ & $\begin{array}{l}\text { AHA } \\
2007^{4}\end{array}$ & $\begin{array}{l}\text { NICE } \\
2008^{21}\end{array}$ \\
\hline \multicolumn{2}{|c|}{$\begin{array}{l}\text { Risk groups described based on } \\
\text { cardiac conditions }{ }^{\star}\end{array}$} & $\begin{array}{l}\text { High, moderate, } \\
\text { negligible }\end{array}$ & High, low & High, moderate & High & High & High \\
\hline \multicolumn{2}{|c|}{$\begin{array}{l}\text { Risk groups where prophylaxis is } \\
\text { recommended or optional }{ }^{\dagger}\end{array}$} & High, moderate & High, low & High, moderate & High & High & - \\
\hline \multirow{5}{*}{$\begin{array}{l}\text { Procedures with } \\
\text { recommendation } \\
\text { for prophylaxis } \ddagger\end{array}$} & Dental & Yes & Yes & Yes & Yes & Yes & No \\
\hline & Respiratory & Yes & Yes & Yes & Yes & Yes & No \\
\hline & Gastrointestinal & Yes & Yes & Yes & Yes & No & No \\
\hline & Genitourinary & Yes & Yes & Yes & Yes & No & No \\
\hline & $\begin{array}{l}\text { Infected skin/ } \\
\text { musculoskeletal }\end{array}$ & Yes & $\mathrm{N} / \mathrm{A}$ & N/A & $\mathrm{N} / \mathrm{A}$ & Yes & $\mathrm{N} / \mathrm{A}$ \\
\hline \multicolumn{2}{|l|}{ Antiseptic rinse } & Yes & Yes & Optional & Yes & No & No \\
\hline
\end{tabular}

*Individual guidelines have classified cardiac conditions into different groups based on their risk for IE. The cardiac conditions included, as well as the risk groups described, differ among individual guidelines. We have tabulated the risk groups described by these guidelines.

†l the setting of a procedure causing bacteremia.

†ln patients with cardiac risk factors.

Yes: Prophylaxis recommended when criteria met; No: Prophylaxis not recommended; N/A: No specific recommendation. Bold typeface used to emphasize the change in recommendations from yes to no.

AHA, American Heart Association; BSAC, British Society for Antimicrobial Chemotherapy; ESC, European Society of Cardiology; NICE, National Institute for Health and Clinical Excellence; SPILF/SFC, Société de Pathologie Infectieuse de Langue Française/ Société Française de Cardiologie. 
Table 2. American Heart Association infective endocarditis prophylaxis recommendations.

Cardiac conditions in which prophylaxis is reasonable

- Prosthetic cardiac valve or prosthetic material used for cardiac valve repair

- Previous infective endocarditis

- Congenital heart disease (CHD)

- Unrepaired cyanotic CHD, including shunts and conduits

- Completely repaired congenital heart defect with prosthetic material or device, during the first 6 months after the procedure

- Repaired CHD with residual defects at or adjacent to site of prosthetic patch or device inhibiting endothelialization

- Post-cardiac transplant valvulopathy

Procedures for which prophylaxis is reasonable (only in patients with above listed high risk cardiac conditions)

- All dental procedures that involve manipulation of gingival tissue or the periapical region of teeth or perforation of oral mucosa

- Invasive procedure of the respiratory tract that involves incision or biopsy of respiratory mucosa

- Procedures involving infected skin, skin structures, or musculoskeletal tissue

Antibiotic prophylaxis solely to prevent infective endocarditis is not recommended for gastrointestinal or genitourinary tract procedures

Reproduced with permission from Wilson et al. Circulation 2007;116:1736-1754. ${ }^{4}$ Copyright 2007 American Heart Association, Inc.

Evidence on the cost effectiveness of antibiotic prophylaxis for at-risk patients undergoing interventional procedures is contradictory as well. ${ }^{12-16}$ Without any clear evidence of benefit, the traditional empiric approach for antibiotic prophylaxis has been in vogue, thus far, primarily thanks to the apprehension about the serious nature of infective endocarditis among physicians, as well as among patients, reinforced by past recommendations from professional societies. Emergence of antibiotic resistance as a significant public health concern combined with the risk of antibiotic-related adverse effects, albeit infrequent, such as anaphylaxis or Clostridium difficile colitis, has prompted a steady move towards an evidence-based approach to infective endocarditis prophylaxis. This is reflected in the recommendations of different professional societies in the last decade (table 1), ${ }^{4,17-21}$

\section{AHA 2007 Guidelines}

The current AHA guidelines depart from the 1997 revision in several aspects. ${ }^{4,17}$ The potential role of daily activities in infective endocarditis causation and the very low yield for antibiotic prophylaxis (cases of infective endocarditis prevented) have been recognized. Prophylaxis has been restricted to only a small number of cardiac conditions with very high risk for adverse outcomes from infective endocarditis (table2). The conditions included are not based on the likelihood of occurrence of infective endocarditis but rather based on the likelihood of adverse outcomes if infective endocarditis occurs in patients with these conditions. As far as the procedures deemed high risk, the major departure from the past is the removal of indication for infective endocarditis prophylaxis for all gastrointestinal and genitourinary procedures. The dental and respiratory procedures requiring prophylaxis have been clarified as those involving manipulation of gingival tissue or the periapical region of teeth, or perforation of oral mucosa and incision or biopsy of respiratory mucosa, respectively. The 2007 AHA recommendations for antibiotic prophylaxis are summarized in table 3 .

\section{National Institute for Health and Clinical Excellence (NICE) Guidance}

NICE guidelines published in 2008 made an even more radical departure from the past. ${ }^{22}$ They do not recommend antibiotic prophylaxis for dental, or non-dental procedures (eg, respiratory, gastrointestinal, and genitourinary). ${ }^{21}$ If a person at risk for infective endocarditis is receiving antibiotic therapy because they are undergoing a gastrointestinal or genitourinary procedure at a site with a suspected infection, antibiotics used should cover organisms that cause infective endocarditis (presumably Enterococci). The guidelines do not make explicit recommendations about procedures involving infected skin and musculoskeletal tissues. Chlorhexidine mouthwash prior to dental procedures is not recommended. A list of cardiac conditions at high risk for developing infective endocarditis is provided primarily for advocating importance of maintaining oral hygiene and increased vigilance for incidence of infective endocarditis (table 4).

The AHA guidelines (2007) and the NICE guidance (2008), ${ }^{21}$ as well as the British Society for Antimicrobial Chemotherapy (BSAC) guidelines (2005), represent significant departure from the traditional approach to infective endocarditis prophylaxis and have been received with initial apprehension among the medical community. ${ }^{23-25}$ Recently more professional societies have incorporated the recommendations of AHA guidelines into their advisory statements. ${ }^{26,27}$ The cause for dissent arises from two important aspects, one being the major departure from traditional recommendations. The second, and probably the most intriguing aspect, is that two professional societies (BSAC and AHA) and NICE have come with three significantly different sets of recommendations, even though all three recognize the paucity of evidence and aim to narrow the indication for prophylaxis. Based on the same body of evidence (lack of evidence for benefit in dental procedures and lack of good epidemiological data for non-dental procedures), BSAC recommends prophylaxis for dental and 
Table 3. Antibiotic prophylactic regimens (AHA 2007)*.

\section{Dental/respiratory procedures ${ }^{\dagger}$}

Regimen: single dose 30 to 60 min before procedure

\begin{tabular}{|c|c|c|c|}
\hline \multirow[b]{2}{*}{ Situation } & \multirow[b]{2}{*}{ Agent } & \\
\hline & & Adults & Children \\
\hline Oral & Amoxicillin & $2 \mathrm{~g}$ & $50 \mathrm{mg} / \mathrm{kg}$ \\
\hline \multirow[t]{2}{*}{ Unable to take oral medication } & $\begin{array}{l}\text { Ampicillin } \\
\text { OR }\end{array}$ & $2 \mathrm{~g}$ IM or IV & $50 \mathrm{mg} / \mathrm{kg}$ IM or IV \\
\hline & cefazolin or ceftriaxone & $1 \mathrm{~g} \mathrm{IM}$ or IV & $50 \mathrm{mg} / \mathrm{kb}$ IM or IV \\
\hline \multirow[t]{3}{*}{ Allergic to penicillins or ampicillin-oral } & $\begin{array}{c}\text { Cephalexin }^{\ddagger \uparrow} \\
\text { OR }\end{array}$ & $2 \mathrm{~g}$ & $50 \mathrm{mg} / \mathrm{kg}$ \\
\hline & $\begin{array}{l}\text { clindamycin } \\
\text { OR }\end{array}$ & $600 \mathrm{mg}$ & 20 mg/kg \\
\hline & azithromycin or clarithromycin & $500 \mathrm{mg}$ & $15 \mathrm{mg} / \mathrm{kg}$ \\
\hline \multirow[t]{2}{*}{$\begin{array}{l}\text { Allergic to penicillins or ampicillin and } \\
\text { unable to take oral medication }\end{array}$} & $\begin{array}{c}\text { Cefazolin or ceftriaxone } \\
\text { OR }\end{array}$ & $1 \mathrm{~g} \mathrm{IM}$ or IV & $50 \mathrm{mg} / \mathrm{kg}$ IM or IV \\
\hline & clindamycin & $600 \mathrm{mg}$ IM or IV & $20 \mathrm{mg} / \mathrm{kg}$ IM or IV \\
\hline
\end{tabular}

\section{Gastrointestinal/genitourinary procedures}

Use of antibiotics solely for prophylaxis not recommended. For procedures involving infected tissue add enterococcal coverage (e.g., amoxicillin, ampicillin, piperacillin or vancomycin) to the therapeutic regimen.

\section{Infected skin and musculoskeletal tissue}

Include an agent active against Staphylococci and $\beta$-hemolytic streptococci (e.g., anti-staphylococcal penicillin or cephalosporin; clindamycin or vancomycin in penicillin allergic patients) in the therapeutic regimen.

\footnotetext{
${ }^{*}$ For patients with cardiac conditions described in table 2.

$\dagger$ For dental and respiratory procedures discussed in table 2.

$\ddagger$ Or other first- or second-generation oral cephalosporin in equivalent adult or pediatric dosage.

I Cephalosporins should not be used in an individual with a history of anaphylaxis, angioedema, or urticaria with penicillins or ampicillin. IM, intramuscular; IV, intravenous.
}

Modified and adapted with permission from Wilson et al. Circulation 2007;116:1736-1754. ${ }^{4}$ Copyright 2007 American Heart Association, Inc.

non-dental (including gastrointestinal and genitourinary), AHA recommends prophylaxis for only dental and respiratory procedures and not gastrointestinal or genitourinary procedures, and NICE recommends prophylaxis for none of the procedures. While these three guidelines differ in their details, they all point toward a general trend against empiric use of antibiotic prophylaxis for infective endocarditis. With the rampant increase in incidence of multi-drug resistant organisms, an evidence-based approach to antibiotic prophylaxis is a healthy trend. Establishing the efficacy and safety of antibiotic prophylaxis with well-designed prospective studies, a yardstick used for acceptance of most medical interventions, should be required for antibiotic prophylaxis as well, considering the significant public health concerns discussed earlier. Subsequent to publishing these guidelines, a Cochrane database review on antibiotics for prophylaxis of bacterial endocarditis in dentistry showed no evidence as to whether penicillin prophylaxis is effective or ineffective against bacterial endocarditis in people at risk who are about to undergo an invasive dental procedure. ${ }^{28}$

\section{Conclusion}

With the NICE guidance, infective endocarditis prophylaxis has come full circle. In the latter half of the $20^{\text {th }}$ century, regular revisions for infective endocarditis prophylaxis guidelines added more cardiac risk conditions and risk groups, more at risk procedures and more antibiotic regimens, adding to the complexity faced by a primary physician in both applying these recommendations to an individual patient and also in explaining the benefits and potential harm to the patient. This created potential for misgivings in physician-patient relationships and medico-legal pitfalls. The newer guidelines are much simpler to follow and could potentially overcome this serious concern. However, explaining these drastic changes to a returning patient and to referral physicians who are more accustomed to old recommendations would be equally challenging, if not more. The upcoming European Society of Cardiology guidelines, expected in 2009 and predicted to be on similar lines to the NICE guidelines, will hopefully help in settling this issue (http://www.escardio.org/guidelines). One of the bright spots in the AHA guidelines is the reduction in the use of prophylactic antibiotics in cases where it can be avoided without serious adverse outcomes. Limited use of prophylaxis will likely reduce the unwanted selection of antibiotic-resistant strains and their unintended consequences such as $C$. difficile-associated colitis. 
Table 4. NICE guidance for infective endocarditis prophylaxis.

Cardiac conditions at high risk for infective endocarditis:

- Acquired valvular heart disease with stenosis or regurgitation

- Valve replacement

- Structural congenital heart disease, including surgically corrected or palliated structural conditions, but excluding isolated atrial septal defect, fully repaired ventricular septal defect or fully repaired patent ductus arteriosus, and closure devices that are judged to be endothelialized

- Previous infective endocarditis

- Hypertrophic cardiomyopathy

Antibiotic prophylaxis is not recommended:

- For people undergoing dental procedures

- For people undergoing non-dental procedures at these sites (upper and lower gastrointestinal; genitourinary tract urological, gynecological and obstetric procedures, and childbirth; upper and lower respiratory tract - includes ear, nose and throat procedures and bronchoscopy)

Chlorhexidine mouthwash is not recommended for infective endocarditis prophylaxis for dental procedures.

Infections in patients at risk for infective endocarditis should be promptly treated to reduce risk of infective endocarditis developing. Antibiotic therapy used for gastrointestinal or genitourinary procedures at a site with suspected infection in patients at risk of infective endocarditis, should cover organisms causing infective endocarditis.

Patients should be educated on benefits and risks of antibiotic prophylaxis, recommendations against antibiotic prophylaxis, importance of oral hygiene, symptoms of infective endocarditis and risks of invasive procedures including non-medical procedures like body piercing and tattooing.

Adapted with permission from BMJ Publishing Group Limited from Stokes et al. Heart 2008;94:930-931. ${ }^{21}$ Copyright 2008 BMJ Publishing Group Limited.

\section{References}

1. Karchmer AW. Infective endocarditis. In: Libby P, Bonow RO, Mann DL, Zipes DP, eds. Braunwald's heart disease: a textbook of cardiovascular medicine. 8th ed. Philadelphia, PA: Saunders Elsevier; 2007. 1713-1738.

2. Moreillon P, Que YA. Infective endocarditis. Lancet 2004;363: 139-149.

3. Tleyjeh IM, Abdel-Latif A, Rahbi H, Scott CG, Bailey KR, Steckelberg JM, Wilson WR, Baddour LM. A systematic review of population-based studies of infective endocarditis. Chest 2007;132:1025-1035.

4. Wilson W, Taubert KA, Gewitz M, Lockhart PB, Baddour LM, Levison M, Bolger A, Cabell CH, Takahashi M, Baltimore RS, Newburger JW, Strom BL, Tani LY, Gerber M, Bonow RO, Pallasch T, Shulman ST, Rowley AH, Burns JC, Ferrieri P, Gardner T, Goff D, Durack DT; American Heart Association Rheumatic Fever, Endocarditis, and Kawasaki Disease Committee; American Heart Association Council on Cardiovascular Disease in the Young; American Heart Association Council on Clinical Cardiology; American Heart Association Council on Cardiovascular Surgery and Anesthesia; Quality of Care and Outcomes Research Interdisciplinary Working Group. Prevention of infective endocarditis: guidelines from the American Heart Association: a guideline from the American Heart Association Rheumatic Fever, Endocarditis, and Kawasaki Disease Committee, Council on Cardiovascular Disease in the Young, and the Council on Clinical Cardiology, Council on Cardiovascular Surgery and Anesthesia, and the Quality of Care and Outcomes Research Interdisciplinary Working Group. Circulation 2007;116:1736-1754. doi: 10.1161/ CIRCULATIONAHA.106.183095.

5. Roberts GJ. Dentists are innocent! "Everyday" bacteremia is the real culprit: a review and assessment of the evidence that dental surgical procedures are a principal cause of bacterial endocarditis in children. Pediatr Cardiol 1999;20:317-325.
6. van der Meer JT, Thompson J, Valkenburg HA, Michel MF. Epidemiology of bacterial endocarditis in The Netherlands. II. Antecedent procedures and use of prophylaxis. Arch Intern Med 1992;152:1869-1873.

7. Strom BL, Abrutyn E, Berlin JA, Kinman JL, Feldman RS, Stolley PD, Levison ME, Korzeniowski OM, Kaye D. Dental and cardiac risk factors for infective endocarditis. A population-based, case-control study. Ann Intern Med 1998; 129:761-769.

8. Shanson DC, Akash S, Harris M, Tadayon M. Erythromycin stearate, $1.5 \mathrm{~g}$, for the oral prophylaxis of streptococcal bacteraemia in patients undergoing dental extraction: efficacy and tolerance. J Antimicrob Chemother 1985;15:83-90.

9. Roberts GJ, Radford P, Holt R. Prophylaxis of dental bacteraemia with oral amoxycillin in children. Br Dent J 1987;162:179-182.

10. Hall G, Heimdahl A, Nord CE. Effects of prophylactic administration of cefaclor on transient bacteremia after dental extraction. Eur J Clin Microbiol Infect Dis 1996;15:646-649.

11. Hall G, Hedström SA, Heimdahl A, Nord CE. Prophylactic administration of penicillins for endocarditis does not reduce the incidence of postextraction bacteremia. Clin Infect Dis 1993; 17:188-194.

12. Caviness AC, Cantor SB, Allen CH, Ward MA. A cost-effectiveness analysis of bacterial endocarditis prophylaxis for febrile children who have cardiac lesions and undergo urinary catheterization in the emergency department. Pediatrics 2004;113:1291-1296.

13. Gould IM, Buckingham JK. Cost effectiveness of prophylaxis in dental practice to prevent infective endocarditis. Br Heart J 1993;70:79-83.

14. Agha Z, Lofgren RP, VanRuiswyk JV. Is antibiotic prophylaxis for bacterial endocarditis cost-effective? Med Decis Making 2005;25:308-320. 
15. Devereux RB, Frary CJ, Kramer-Fox R, Roberts RB, Ruchlin HS. Cost-effectiveness of infective endocarditis prophylaxis for mitral valve prolapse with or without a mitral regurgitant murmur. Am J Cardiol 1994;74:1024-1029.

16. Clemens JD, Ransohoff DF. A quantitative assessment of pre-dental antibiotic prophylaxis for patients with mitral-valve prolapse. J Chronic Dis 1984;37:531-544.

17. Dajani AS, Taubert KA, Wilson W, Bolger AF, Bayer A, Ferrieri P, Gewitz MH, Shulman ST, Nouri S, Newburger JW, Hutto C, Pallasch TJ, Gage TW, Levison ME, Peter G, Zuccaro G Jr. Prevention of bacterial endocarditis. Recommendations by the American Heart Association. JAMA 1997;277:1794-1801.

18. Danchin N, Duval X, Leport C. Prophylaxis of infective endocarditis: French recommendations 2002. Heart 2005;91:715-718.

19. Horstkotte D, Follath F, Gutschik E, Lengyel M, Oto A, Pavie A, Soler-Soler J, Thiene G, von Graevenitz A, Priori SG, Garcia MA, Blanc JJ, Budaj A, Cowie M, Dean V, Deckers J, Fern·ndez Burgos E, Lekakis J, Lindahl B, Mazzotta G, Morais J, Oto A, Smiseth OA, Lekakis J, Vahanian A, Delahaye F, Parkhomenko A, Filipatos G, Aldershvile J, Vardas P; Task Force Members on Infective Endocarditis of the European Society of Cardiology; ESC Committee for Practice Guidelines (CPG); Document Reviewers. Guidelines on prevention, diagnosis and treatment of infective endocarditis executive summary; the task force on infective endocarditis of the European Society of Cardiology. Eur Heart J 2004;25:267-276.

20. Gould FK, Elliott TS, Foweraker J, Fulford M, Perry JD, Roberts GJ, Sandoe JA, Watkin RW, Working Party of the British Society for Antimicrobial Chemotherapy. Guidelines for the prevention of endocarditis: report of the Working Party of the British Society for Antimicrobial Chemotherapy. J Antimicrob Chemother 2006;57:1035-1042.

21. Stokes T, Richey R, Wray D; Guideline Development Group. Prophylaxis against infective endocarditis: summary of NICE guidance. Heart 2008;94:930-931.

22. NICE Short Clinical Guidelines Technical Team. Prophylaxis against infective endocarditis: antimicrobial prophylaxis against infective endocarditis in adults and children undergoing interventional procedures. London: National Institute for Health and Clinical Excellence; 2008. NICE Clinical Guideline 64.

23. Gibbs JL, Cowie M, Brooks N. Comment on: guidelines for the prevention of endocarditis: report of the Working Party of the British Society for Antimicrobial Chemotherapy. J Antimicrob Chemother 2006;58:896; author reply 896-898.

24. Ashrafian H, Bogle RG. Antimicrobial prophylaxis for endocarditis: emotion or science? Heart 2007;93:5-6.

25. Shanson D. New British and American guidelines for the antibiotic prophylaxis of infective endocarditis: do the changes make sense? A critical review. Curr Opin Infect Dis 2008;21:191-199.

26. Wright TI, Baddour LM, Berbari EF, Roenigk RK, Phillips PK, Jacobs MA, Otley CC. Antibiotic prophylaxis in dermatologic surgery: advisory statement 2008. J Am Acad Dermatol 2008;59:464-473.

27. Wolf JS Jr, Bennett CJ, Dmochowski RR, Hollenbeck BK, Pearle MS, Schaeffer AJ; Urologic Surgery Antimicrobial Prophylaxis Best Practice Policy Panel. Best practice policy statement on urologic surgery antimicrobial prophylaxis. J Urol 2008;179:1379-1390.

28. Oliver R, Roberts GJ, Hooper L, Worthington HV. Antibiotics for the prophylaxis of bacterial endocarditis in dentistry. Cochrane Database Syst Rev 2008;(4):CD003813.
Author Affiliations

Prabhakaran P. Gopalakrishnan, $M D$

Department of Internal Medicine

JPS Health Network

Fort Worth, Texas

Sanjay K. Shukla, PhD

Marshfield Clinic Research Foundation

Marshfield, Wisconsin

Tahir Tak MD, PhD, FACC

Cardiovascular Diseases

Franciscan Skemp Healthcare/Mayo Health System

La Crosse, Wisconsin 